7. Child Lang. 30 (2003), 67 I-679. (C) 2003 Cambridge University Press

DOI: I0.1017/So305000903005683 Printed in the United Kingdom

N O T E

\title{
Relative clause comprehension revisited: commentary on Eisenberg (2002)*
}

\author{
EVAN KIDD \\ Max Planck Child Study Centre, University of Manchester \\ (Received 28 May 2002. Revised 24 October 2002)
}

\begin{abstract}
Eisenberg (2002) presents data from an experiment investigating threeand four-year-old children's comprehension of restrictive relative clauses (RC). From the results she argues, contrary to Hamburger \& Crain (1982), that children do not have discourse knowledge of the felicity conditions of RCs before acquiring the syntax of relativization. This note evaluates this conclusion on the basis of the methodology used, and proposes that an account of syntactic development needs to be sensitive to the real-time processing requirements acquisition places on the learner.
\end{abstract}

\section{NTRODUCTION}

Research on the acquisition of relative clauses (RCs) has had a long history in child language. Studies of children's productions have shown that children begin producing relative structures from around two years of age, albeit in a structurally impoverished form (Limber, I 973; Crain, McKee \& Emiliani, I 990; McKee, McDaniel \& Snedeker, i 998; Diessel \& Tomasello, 2000). The results from comprehension studies have been less conclusive. Early comprehension studies suggested that children had little knowledge of the recursive properties of English that allow formation of RCs (e.g. Sheldon, I 974; Tavakolian, I 98I). Other comprehension studies provided appropriate pragmatic conditions for children to process the restrictive $\mathrm{RCs}$ as noun modifiers; these studies showed that young children understood these sentences, and that acquisition of the structural variations of RCs progressed incrementally according to the relative complexity of the structure type

[*] I would like to thank Edith L. Bavin for helpful comments on an earlier version of this paper. Remaining errors are my own. Address for correspondence: Evan Kidd, Max Planck Child Study Centre, University of Manchester, Manchester Mi 3 9PL, UK. tel: (o)I6r 275 2594; e-mail : evan.j.kidd@man.ac.uk 
(Córrea, I995; Kidd \& Bavin, 2002). Eisenberg (2002) claims to have provided appropriate pragmatic conditions to test children's knowledge of the function of RCs. However, this can be questioned; the conclusions she makes do not seem warranted.

Consider the relative construction in (I):

(I) The cow pushed the horse [that_jumped over the fence].

$\mathrm{RC}$ constructions vary according to their embeddedness and focus. The RC in (I) that jumped over the fence is right-branching, modifying the object NP in the main clause. Focus refers to the role the modified noun plays in the $\mathrm{RC}$, as signified by the underscore gap in (I) which has subject focus. Thus the $\mathrm{RC}$ in ( $\mathrm{I}$ ) can be identified as OS.

$A$ restrictive $\mathrm{RC}$ identifies a unique token of the noun it modifies. For instance, sentence (I) identifies a particular horse (the one that jumped over the fence) out of a hypothetical set of horses. In order for (I) to be felicitous there should exist more than one horse in the discourse setting. Otherwise the RC is redundant. Early studies (e.g. Sheldon, I974; Tavakolian, I98 I) investigating children's knowledge of RCs did not provide a felicitous discourse context in which to process the test sentences. For instance, for sentence (I) children were provided with one toy cow, one toy horse, and a toy fence. They were asked to act out the sentence using the toy props. Findings from these studies indicated that young children do not process RCs well, although the results across studies were not consistent.

Hamburger \& Crain (I982) argued that the failure of young children to comprehend sentences with RCs could be attributed to methodological problems. The use of only one animal of each type rather than a set from which to choose violates the semantic/pragmatic aspects of language use. They showed that children were able to enact sentences containing OS RCs with more accuracy when these felicity conditions were met. Eisenberg (2002) systematically investigated whether children actually use this information by manipulating the number of tokens of the NP referents in sentences like (I). In a condition replicating Hamburger \& Crain there were two horses and one cow (Biased felicitous - BF). In a neutral felicitous (NF) condition there were two horses and two cows. In a neutral infelicitous (NI) condition there was one horse, one cow, and a distracter toy such as a sheep. Finally, in a biased infelicitous (BI) condition there were two cows and one horse. Eisenberg tested the SS construction, where the RC is centreembedded, as well as the OS construction. It was predicted, following Hamburger \& Crain's conclusion that children know felicity conditions of relativization, that children would perform best in the $\mathrm{BF}$ condition, followed by the NF condition, and worst in the NI condition. No prediction was made for the BI condition, although one would presume that performance would be near or equal to that in the NI condition. The results did not support these 
predictions, showing that children interpreted the structures with equal accuracy (approx. 50\%) in each condition. Eisenberg concluded that children aged three and four years are insensitive to the pragmatic principles of relativization, and that children's difficulty in interpreting relative clauses at this age is due to syntactic limitations.

The present paper raises two questions in response to Eisenberg's (2002) study. First, the utility of the act out methodology is discussed. Second, the kind of data the act out methodology provides is considered.

\section{A methodological objection: the inappropriateness of the standard act-out task}

Providing more than one token of the head referent (as did Eisenberg, 2002) only PARTIALLY meets the felicity conditions for RC interpretation. Córrea (I 995) has discussed this in detail, suggesting that this version of the act-out task (the 'standard' act-out task) presents children with conflicting task demands (see also Hamburger \& Crain, I 984; for other arguments against the utility of providing more than one token of head referent see Goodluck, I 990). Córrea argued that the method involves a metalinguistic task ('game with language') disguised in the context of a 'game with toys'; successful completion of the task requires that children attend to the test sentence devoid of context and then translate the resulting semantic representation into actions with the toys provided. In this experimental setting the NPs in the sentence have no real referential function, and the $\mathrm{RC}$ has no functional purpose, as the head referent has not been previously identified in discourse.

Córrea ( I 995) overcame the problem by creating an alternative act-out task where children could process restrictive RCs as pragmatically functional noun modifiers. Prior to hearing the test sentence children heard two background scenes, such as in $(2 a)$ :

(2a) A horse jumped over the fence. Another horse ate the grass.

After the experimenter acted out the background scenes the child was asked to act out the test sentence, as in $(2 b)$ :

(2b) The cow pushed the horse that jumped over the fence

The alternative act-out task satisfies the functional requirements of the RC comprehension, namely, the discourse continuity of the head referent, and the need for more than one token of the head referent. The question asked by experimenters using this task is not whether children use felicity conditions to interpret RCs; the assumption is that by definition a RC construction requires that the felicity conditions be met.

When tested using the alternative act-out task the nature of children's syntactic knowledge becomes more apparent. Kidd \& Bavin (2002) tested three, four, and five-year-old English-speaking children's knowledge of 
restrictive RCs using the task; however, children were tested on structures containing three animate NPs rather than two. Using three animate NPs is a more rigorous test of children's processing capabilities (see Córrea, I 995). The age group most comparable to Eisenberg's data (four-year-olds, mean age $=4 ; 3$ ) interpreted the SS structure correctly on $39 \%$ of trials, and the OS structure correctly on $68 \%$. A clear developmental progression was observed across age groups, with children interpreting right-branching structures more easily than centre-embedded structures, which were mastered by five years of age. This result supports those investigations of children's spontaneous productions, which have shown that children produce rightbranching before centre-embedded relatives (see Limber, I973; Diessel \& Tomasello, 2000).

Eisenberg's (2002) results could be attributed to the infelicitous nature of the standard act-out task. In fact it appears that the children applied a conjoined-clause analysis $(\mathrm{NVN}+\mathrm{NVN})$ to the test structures, as described by Tavakolian (I98I). That is, children acted out the test sentences as conjoined simple sentences. The data show that children acted out the first NVN sequence in the test sentences with almost perfect accuracy (96\% for OS sentences and $95 \%$ for SS sentences). Performance tapered off in the second NVN sequence, with children only performing the correct action on approximately $50 \%$ of trials. The majority of incorrect responses saw children performing the second NVN sequence with the incorrect animate NP referent, suggesting that they were selecting the agent of the second clause at chance levels. Children acted the first NVN sequence of both structural variations of the test sentences first. Although it is correct to act out the first NVN sequence in an SS sentence because this sequence encodes the RC, it does not make sense to do so in an OS sentence because this results in acting out the main clause BEFORE the RC. That is, acting out the main clause first for the OS construction does not respect the temporal sequence of events that the sentence encodes.

\section{Children's knowledge of relative clauses}

Providing children with appropriate discourse conditions results in improved performance in relative clause comprehension. However, those studies that have used Córrea's ( I 995) alternative act-out task have not shown children to exhibit adultlike knowledge of restrictive RCs until five years of age (Córrea, I995; Kidd \& Bavin, 2002). This is despite younger children exhibiting knowledge of relativization through their productions.

If children produce well-formed relative clause constructions then it can be argued that they have mastered the syntax of the language. Research across various languages has shown that children do produce a range of structurally different relative clauses by around three years of age, the frequency 
of use depending on the input language and discourse factors (Crain et al., I 990; Dasinger \& Toupin, r 994; McKee et al., I 998; Diessel \& Tomasello, 2000; McKee \& McDaniel, 200 I). McKee et al. ( I 998) reported data from an elicited production task, showing that children as young as $2 ; 2$ were capable of producing RCs that modify NPs restrictively (as in that one that's jumping on the table). Diessel \& Tomasello (2000), working from a functionalist perspective, analysed RCs in young children's spontaneous speech. They showed that children's earliest RCs occur in presentational constructions that express a single proposition in two finite clauses, as in (3).

(3) Here's a tiger that's gonna scare him

A decrease in the proportion of presentational constructions was observed between three and four years, which coincided with an increase in the use of more complex constructions where the $\mathrm{RC}$ is attached to a noun in a fullfledged main clause. Children preferred to modify the object NP of the main clause, supporting an observation made by Slobin (I973), who suggested that children prefer not to interrupt the main clause. The increase in use of complex constructions was accompanied by an increase in transitive RCs. This suggests that children gradually become able to express more complex propositions within the embedded clause as they grow older.

When children's performance on comprehension tasks appears to underestimate their grammatical knowledge as indicated by their productions, we are left to explain the difference. That is, why does the child who produces (4) (from Diessel \& Tomasello, 2000) not understand (5)?

(4) The first thing we have to do (is to) put dis in

(5) The dog that bumped the cow jumped over the pig

There are several, perhaps related, answers to this question. First, children rarely, if ever, hear sentences like (5). These types of sentences are strong tests of children's grammatical knowledge because they provide no clues to interpretation. Compare (5) to (6),

(6) The dog that chased the cat ate the bone

Sentence (6) is intuitively easier to understand than (5), for a number of reasons. First, there are two animate NPs in (6), but three in (5). Animacy has been shown to affect processing complexity in both children and adults (Goodluck \& Tavakolian, I 982; Córrea, I995; Mak, Wiestske \& Schriefers, 2002). Second, the propositions the two clauses express (dog chase cat/dog eat bone) are familiar, scripted real world events ( $f$. dog bump cow/dog jump over pig). The relationships between the NP referents are thus easier to compute. The suggestion here is that act-out comprehension experiments, in the first instance, are off-line measures of how children PROcEss test structures. Thus 
the data from these experiments must be interpreted within an account of processing. If a difference between structure types and between age groups is observed, then some hypotheses can be made about possible developmental mechanisms. For instance, syntactic complexity appears to have a mediating role in the acquisition of relative clauses, which is likely to be related to processing capacity (Gibson, I998).

The question to be asked, then, is what is the relationship between language processing and language acquisition? A processing explanation of Eisenberg's (2002) results might propose that children's parsers were overtaxed due to the infelicitous demands of the task. In recent research investigating the status of resumptive pronouns in English relative clauses McKee \& McDaniel (200I) present data that suggests the child's parser overrides the grammar. Children $\left(3 ; 5^{-8}\right.$; I I $)$ and adults participated in two elicited production studies and a grammatical judgment task. Although the youngest participants produced relative clause structures in a manner very similar to adults, children were more likely to accept as grammatical relative clauses structures containing resumptive pronouns in positions not allowed by the grammar, as in (7).

(7) This is the man that he's swimming

McKee \& McDaniel (200I) suggest that the willingness to accept this sentence as grammatical reflects a parsing effect whereby completed clauses are shunted out of active memory. As the completed first clause in (7) (this is the $\operatorname{man}_{t}$ ) contains a filler for a later gap (that t's swimming), the gap's interpretation is difficult without the active trace, and so the resumptive pronoun serves as a prop to reactivate the discourse referent to which the trace co-refers. Dickey (r996) has shown that this effect occurs in adults when sentences have three clauses. McKee \& McDaniel suggest that the effect occurs in children when sentences have only two clauses because the child shunts clauses early. Such an approach suggests a role for working memory in language processing and language acquisition (see Booth, MacWhinney \& Harasaki, 2000). This is in turn consistent with arguments made by Newport ( I 990) and Elman ( I 993), who have both considered how a limited resource capacity affects the acquisition process.

There has traditionally been little place for processing explanations in child language research (but see papers in Frazier \& de Villiers, I 990). Parsing mechanisms have generally been invoked to explain non-adult linguistic behaviour rather than to explain acquisition per se. Fodor (1998a,b) has written about this issue at length, arguing that the input has no structure or meaning other than what the learner imposes on it. The suggestion is that input must be segmented and parsed from its initial acoustic form into a form readily accessible to higher cognition before learning can take place. Thus the parser is necessarily implicated in acquisition. 
Fodor's (I 998 $a, b$ ) argument represents an approach to the study of acquisition that, although implicit in many researchers' thoughts, has received little empirical attention (beyond infant speech perception). There are both methodological and theoretical reasons for why this is so. On the methodological side, the methodologies traditionally used to study language processing in adults are often inappropriate to use with children (McKee, I996). Recent technological advances have enabled child language researchers to begin to bridge the gap between processing and acquisition (Trueswell, Sekerina, Hill \& Logrip, I999; Booth et al., 2000). On the theoretical side, processing explanations have been disfavoured by researchers assuming continuity of processing (e.g. Crain \& Thornton, r 998). These researchers argue against the notion that processing can shape the acquisition process because to admit so leads to issues of learnability. The argument is that children must begin the acquisition process with adult-like parsers because otherwise they could not make use of the input. However, it is not unreasonable to suggest that some features of the developing parser, such as resource capacity and the efficiency with which multiple sources of information are integrated (see Trueswell et al., I 999), differ from the adult state. Such differences need not violate the central assumptions of the generative framework - modularity and linguistic competence. Indeed, structural models of adult sentence processing preserve these assumptions by appealing to parsing strategies that are functionally motivated in terms of more general cognitive faculties (e.g. Frazier, I987). Child language researchers wishing to invoke processing explanations within the nativist tradition are thus able to maintain the assumptions of competence and modularity if they appeal to mechanisms outside of the language system, albeit mechanisms that have direct bearing on how language is processed.

The alternative is that modularity and competence are not assumed. Researchers such as Bates \& MacWhinney (1989) and Seidenberg \& MacDonald (I999) identify adult performance as the child's target rather than a competence grammar, and argue that acquisition is driven by a generalcognitive learning mechanism. Here no distinction is made between language processing and language acquisition; acquisition is the outcome of an accumulation of probabilistic cues to interpretation. This approach identifies a central role for distributional analysis. Aspects of the language that have high cue reliability are acquired before rarer linguistic patterns. On this approach, Eisenberg's (2002) participants' tendency to invoke the conjoined-clause analysis would reflect a canonical sentence strategy (Bever, I 970; Townsend \& Bever, 200I).

CONCLUSION

The present note has argued against the conclusions Eisenberg (2002) made from her study investigating children's use of pragmatic information in 
their interpretation of relative clauses. It has been argued that whether or not children know the pragmatic principles for interpreting relative clauses is secondary to the fact that the conditions from which these principles arise are required to be met for acquisition to take place. Only when these pragmatic conditions have been satisfied in an experiment can an accurate estimate of children's grammatical knowledge be made. Córrea's ( I 995) modified act-out task, which is sensitive to the functional role of relative clauses in discourse, better taps into children's emerging knowledge of relativization. It was also argued that an account of syntactic development must be sensitive to the information processing requirements acquisition places on the language learner. This highlights the importance of studying language phenomena using multiple experimental techniques, and of developing sensitive on-line techniques that investigate children's immediate processing of language.

\section{REFERENCES}

Bates, E. \& MacWhinney, B. (I989). Functionalism and the competition model. In B. MacWhinney \& E. Bates (eds), The crosslinguistic study of sentence processing. Cambridge: CUP.

Bever, T. G. (1970). The cognitive basis for linguistic structures. In J. R. Hayes (ed.), Cognition and the development of language. New York: John Wiley \& Sons.

Booth, J. R., MacWhinney, B. \& Harasaki, Y. (2000). Developmental differences in visual and auditory processing of complex sentences. Child Development $\mathbf{7 4}, 98 \mathrm{I}-\mathrm{I} 003$.

Córrea, L. M. (1995). An alternative assessment of children's comprehension of relative clauses. Fournal of Psycholinguistic Research 24, I 83-203.

Crain, S., McKee, C. \& Emiliani, M. ( 1990 ). Visiting relatives in Italy. In L. Frazier \& J. de Villiers (eds), Language processing and language acquisition. Dordrecht: Kluwer.

Crain, S. \& Thornton, R. (1998). Investigations in Universal Grammar. Cambridge, MA: MIT Press.

Dasinger, L. \& Toupin, C. (I 994). The development of relative clause functions in narrative. In R. A. Berman \& D. I. Slobin (eds), Relating events in narrative: a crosslinguistic developmental study. Hillsdale, $\mathrm{NJ}$ : Erlbaum.

Dickey, M. (I 996). Constraints on the sentence processor and the distribution of resumptive pronouns. In M. Dickey \& S. Tunstall (eds), UMOP I9: Linguistics in the Laboratory. Amherst, MA: GLSA.

Diessel, H. \& Tomasello, M. (2000). The development of relative clauses in spontaneous child speech. Cognitive Linguistics II, I 3 I-5 I.

Elman, J. (I 993). Learning and development in neural networks: the importance of starting small. Cognition 48, 7 I-99.

Eisenberg, S. (2002). Interpretation of relative clauses by young children: another look. Fournal of Child Language 29, I77-88.

Fodor, J. D. (1998a). Learning to parse. Fournal of Psycholinguistic Research 27, 285-3 I 9.

Fodor, J. D. (1 998b). Parsing to learn? Fournal of Psycholinguistic Research 27, 339-74.

Frazier, L. (1987). Sentence processing : a tutorial review. In M. Coltheart (ed.), Attention and performance XII : the psychology of reading. Hillsdale, NJ : Erlbaum.

Frazier, L. \& de Villiers, J. (eds) (I990). Language processing and language acquisition. Dordrecht: Kluwer.

Gibson, E. (1998). Linguistic complexity: locality of syntactic dependencies. Cognition 68, I-79. 
Goodluck, H. (I990). Knowledge integration in processing and acquisition: comments on Grimshaw \& Rosen. In L. Frazier \& J. de Villiers (eds), Language processing and language acquisition. Dordrecht: Kluwer.

Goodluck, H. \& Tavakolian, S. (I982). Competence and processing in children's grammar of relative clauses. Cognition II , I-27.

Hamburger, H. \& Crain, S. (I982). Relative acquisition. In S. Kuczaj II (ed.), Language development vol. I : Syntax and semantics. Hillsdale, NJ : Erlbaum.

Hamburger, H. \& Crain, S. (1984). Acquisition of cognitive compiling. Cognition 1 7, 85-1 36.

Kidd, E. \& Bavin, E. L. (2002). English-speaking children's understanding of relative clauses: evidence for universal-cognitive and language-specific constraints on development. Fournal of Psycholinguistic Research 31, 599-6 I 7.

Limber, J. (1973). The genesis of complex sentences. In T. Moore (ed.), Cognitive development and the acquisition of language. New York: Academic Press.

Mak, W. M., Wietske, V. \& Schriefers, H. (2002). The influence of animacy on relative clause processing. Fournal of Memory and Language 47, 50-68.

McKee, C. (1996). On-line methods. In D. McDaniel, C. McKee \& H. S. Cairns (eds), Methods for assessing children's syntax. Cambridge, MA: MIT Press.

McKee, C. \& McDaniel, D. (200I). Resumptive pronouns in English relative clauses. Language Acquisition 9, I I 3-56.

McKee, C., McDaniel, D. \& Snedeker, J. (1998). Relatives children say. Fournal of Psycholinguistic Research 27, 573-96.

Newport, E. L. (I 990). Maturational constraints on language learning. Cognitive Science I4, I I-28.

Seidenberg, M. S. \& MacDonald, M. C. (I999). A probabilistic constraints approach to language acquisition and processing. Cognitive Science 23, 569-88.

Sheldon, A. (1974). The role of parallel function in the acquisition of relative clauses in English. Fournal of Verbal Learning and Verbal Behaviour 13, 272-81.

Slobin, D. I. ( I 973). Cognitive prerequisites for the development of grammar. In C. A. Ferguson \& D. I. Slobin (eds), Studies of child language development. New York, NY: Holt, Rinehart \& Winston.

Tavakolian, S. (I98I). The conjoined clause analysis of relative clauses. In S. Tavakolian (ed.), Language acquisition and linguistic theory. Cambridge, MA: MIT Press.

Townsend, D. J. \& Bever, T. G. (200I). Sentence comprehension: the integration of habits and rules. Cambridge, MA: MIT Press.

Trueswell, J. C., Sekerina, I., Hill, N. M. \& Logrip, M. L. (I 999). The kindergarten-path effect: studying on-line sentence processing in young children. Cognition 73, 89-I 34 . 